\title{
New Design of Aluminum 6061 Welding Joining Using Friction Stir Welding Method
}

\author{
Widia Setiawan ${ }^{*}$, Nugroho Santoso, Surojo \\ Departement of Mechanical Engineering Sekolah Vokasi University of Gadjah Mada, \\ Yogyakarta, Indonesia \\ *Corresponding author: widia_s@ugm.ac.id
}

\begin{abstract}
Parallel, lap, corner, and $\mathrm{T}$ joints are commonly used in fusion welding and solid welding. Other joints made are lap and butt joint. This study aims to evaluate a new design of fitting model single $U$ and double $\mathrm{U}$ for friction stirr welding of Aluminum. Aluminum sheet 6061 with a thickness of $10 \mathrm{~mm}$, will be cut to a length of $150 \mathrm{~mm}$ and a width of $100 \mathrm{~mm}$, then a locking groove will be made with an inner size of $5 \mathrm{~mm}$ and a length of $150 \mathrm{~mm}$ The flow is used to be paired in the FSW process. This experiment results show the high tensile strength that occurs in the double joint $\mathrm{u}$, is $13.4 \mathrm{kN}$ while the average is $12 \mathrm{kN}$. Single connection experiment $\mathrm{u}$ the highest tensile strength is $12.89 \mathrm{kN}$, while the average value is $10.37 \mathrm{kN}$. The hardness is higher in double $\mathrm{u}$ joints compared to single $\mathrm{u}$ joints.

Copyright (C) 2020. Journal of Mechanical Engineering Science and Technology.

All rights reserved.
\end{abstract}

Keywords: Aluminum welding, double $U$, friction stir welding, lap butt joint, single $U$

\section{Introduction}

Friction Stir Welding (FSW) is a solid-phase joining technique on fabrication industry. Good quality single-sided and double-sided butt, “T”, and lap joints. It was invented in 1991 and was originally used to produce butt joints of aluminum alloys [1]. FSW is a method of welding solid metals, capable of connecting two different metals (dissimilar metal) in plastic conditions. The probe is a solid welding aid to produce heat and make the material plastic. This connection occurs because the plastic material is continuously stirring along the joint line. This method was discovered and patented by The Welding Institute (TWI) [1]. FSW combine two ferrous or non-ferrous metals without the metal transfer, under pressure or without pressure. It have applied to metals and does not change its basic characteristics. The FSW is often applied to Aluminum and not post weld heat treatment (PWHT). PWHT is heat-treatment of metal after welding with the aim of reducing residual stresses [2].

FSW has several advantages including, metals low carbons with good weldability, low heat energy, no electrodes, no residual stress, low distortion, good appearance welds at relatively and low cost. The relative motion between the rotating tool and the substrate generates frictional heat that creates a plasticized region around the immersed portion of the tool [3]. The success of the FSW process depends on the design, diameter, and probe material that will be used. The probe consists of a shoulder, arm, and pin, each part of which functions as follows: a heat-producing shoulder, a chuck grip arm on the engine, and a pin as a plastic 
material stirrer. Pressure of $18.7 \mathrm{kN}$ apply to the materials, then the pressure will be reduced by a certain speed [4].

The base materials for welding were AA6063 (Al- $0.7 \% \mathrm{Mg}-0.4 \% \mathrm{Si}$ ) aluminum alloy and AA5052 (Al-2.5\%Mg) aluminum alloy. The thicknesses of the AA6063 plate and the AA5052 plate were $4 \mathrm{~mm}$ and $2 \mathrm{~mm}$, respectively. The plates were friction stir welded vertical to their rolling directions. The so-called lap-butt joint of dissimilar to AA6063/AA5052 aluminum alloys consisting of three plates [5].

The material structure during FSW is shown at Figure 1. During the welding process, the heat is generated from the friction by the probe that spins on the work-piece which eventually creates plastic state compound. This state can be observed in the thermomechanically affected zone (TMAZ) [6].

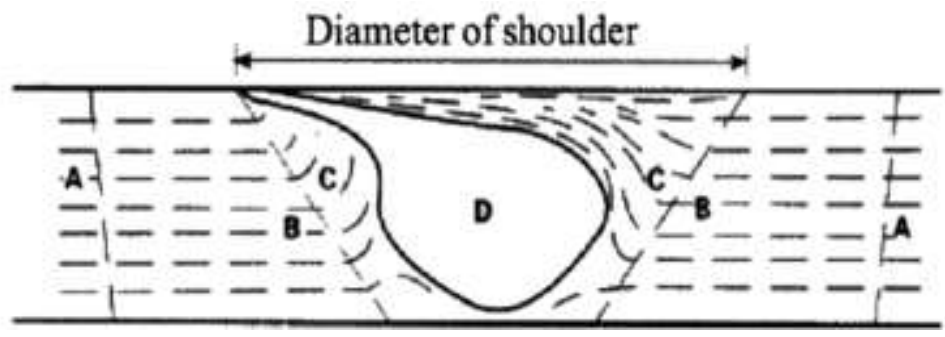

Fig. 1. FSW process in metal: a) Parent metal, b) Haz on FSW, c) TMAZ on FSW, d) Plastic on FSW [6]

The FSW has become an efficient option of welding method for the same or dissimilar aluminum alloys, especially those which are difficult or impossible to be welded by the conventional fusion welding without any hot crackings, blow holes or distortions [7]. Lap connection is a connection process by overlapping or stacked, then the probe is rotated on a pile material (Figure 2). The length of the pin penetrates the two materials, then the connection process is carried out with the probe rotated and shifted on the workpiece surface [8]. Key features on T- Joint FSW optimization are $1000 \mathrm{rpm}$ rotation speed, $15 \mathrm{~mm}$ shoulder diameter, $3.9 \mathrm{~mm}$, and $2.5 \mathrm{~mm}$ in aluminum thickness [9].

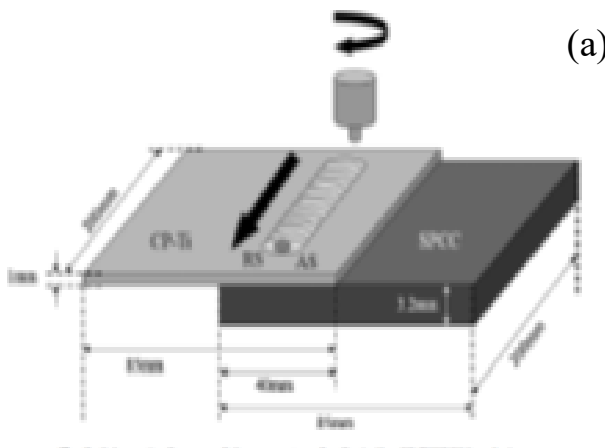

(a)

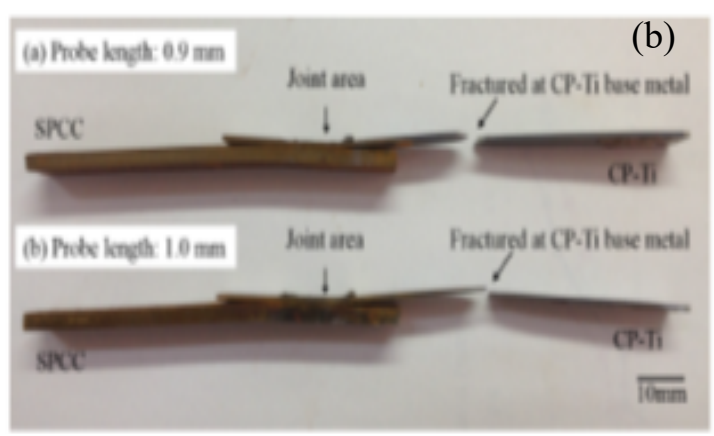

Fig. 2. a) FSW lap joint process, b) Tensile fracture test [8]

FSW is a current technique in joining aluminum without feeder electrode required. The heat is generated from the rotation of welding tool which results in deformation in the welding area. This joining process is called solid welding [10]. The heat is generated from the spindle rotation and the joining occurs because of the radial force toward the axial 
direction. The higher the pressure, the more heat is generated. Such condition will greatly influence the result of the welding and affect the material's mechanic state [11]. FSW is a welding method for two Ferro or non-Ferro metals without liquefication and can be done with or without pressure. FSW does not alter the basic characteristics of the metals and is often performed to aluminum that does not endure post weld heat treatment (PWHT) PWHT is heat-treatment of metal after welding with the aim of reducing residual stresses [12].

The heat in FSW technique is influenced by the probe's diameter. Its size will affect the formation of microstructure, macrostructure, and the tensile strength on the welding of the dissimilar metals between Al 6061 dan AZ 31 Magnesium [13]. The micro hardness value above $52 \mathrm{HVn}$ was formed by all joint variations on $30 \mathrm{~mm} / \mathrm{min}$ feedrate speed because the temperature distribution with such speed was low, therefore the Magnesium loss was just minimum. The highest tensile test score was $163.7 \mathrm{MPa}$ by C-B 45 joint on $10 \mathrm{~mm} / \mathrm{min}$ feedrate speed. The temperature distribution reached $420^{\circ} \mathrm{C}$, consequently forming plastic state on the work-piece [14]. This study aims to evaluate a new design of fitting model single $\mathrm{U}$ and double $\mathrm{U}$ for FSW in Aluminum welding.

\section{Material and Methods}

The aluminum 6061 as the object of this research contain chemical substance as described in Table 1.

Table 1. Chemical composition of 6061 aluminum alloy (wt.\%)

\begin{tabular}{lccccccccc}
\hline Compositions & $\mathrm{Mg}$ & $\mathrm{Si}$ & $\mathrm{Cu}$ & $\mathrm{Mn}$ & $\mathrm{Fe}$ & $\mathrm{Cr}$ & $\mathrm{Ti}$ & $\mathrm{Zn}$ & $\mathrm{Al}$ \\
\hline Content & 0.9 & 0.6 & 0.25 & 0.086 & 0.18 & 0.1 & 0.192 & 0.01 & $\mathrm{Bal}$ \\
\hline
\end{tabular}

The probe was made from low carbon steel with hardened EMS 45, simple design and with size is shown in Figure 1, then hardened to $62 \mathrm{HRc}$

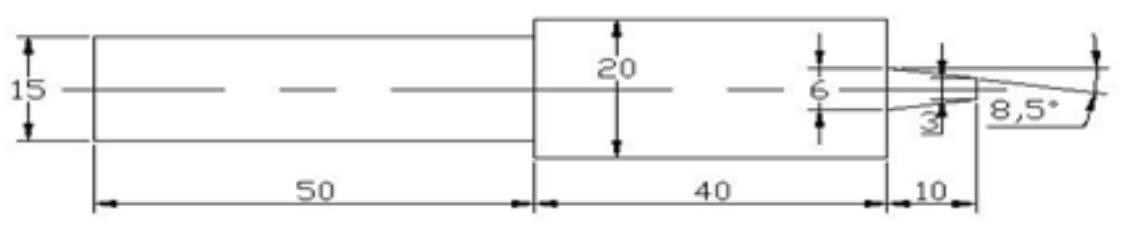

Fig. 3. Simple Design of probe with EMS 45 materials

Table 2. Chemical composition of 6061 aluminum alloy (wt.\%)

\begin{tabular}{lllll}
\hline Compositions & $\mathrm{Mn}$ & $\mathrm{C}$ & $\mathrm{Si}$ & $\mathrm{Fe}$ \\
\hline Contens & 0.486 & 0.450 & 0.156 & $\mathrm{Bal}$ \\
\hline
\end{tabular}

Before welding 6061 aluminum sheets were made in pairs of single $U$ and double $U$ grooves using a CNC machine as shown in Figure 2 and Figure 3. It is used $2000 \mathrm{rpm}$ motor 
speed and $10 \mathrm{~mm} / \mathrm{min}$. feed rate. This study measured the temperature manually using a simple thermocouple measuring instrument that has been calibrated (portable temperature).

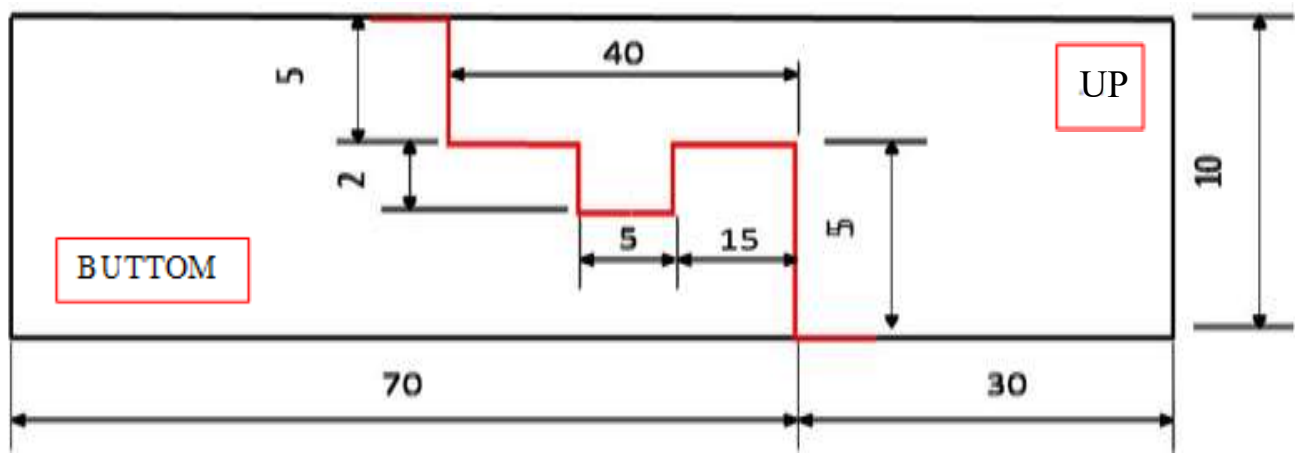

Fig. 4. New design single U joint of the aluminum 6061 for FSW

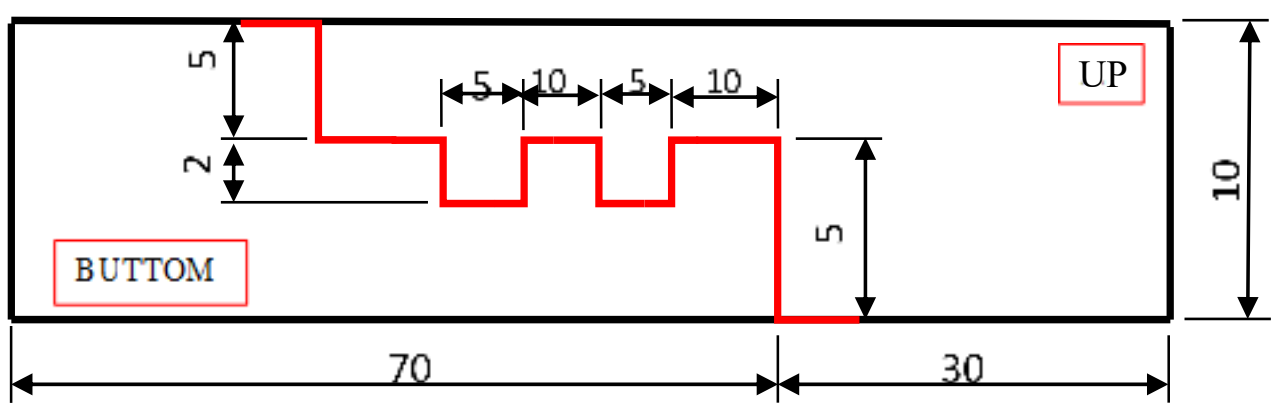

Fig. 5. New design double U joint of the aluminum 6061 for FSW

This research emphasizes on the new joint design, namely single $U$ and double $U$, then the strength is compared. The welded joint is used only as a lock, while the tensile strength lies in the design.
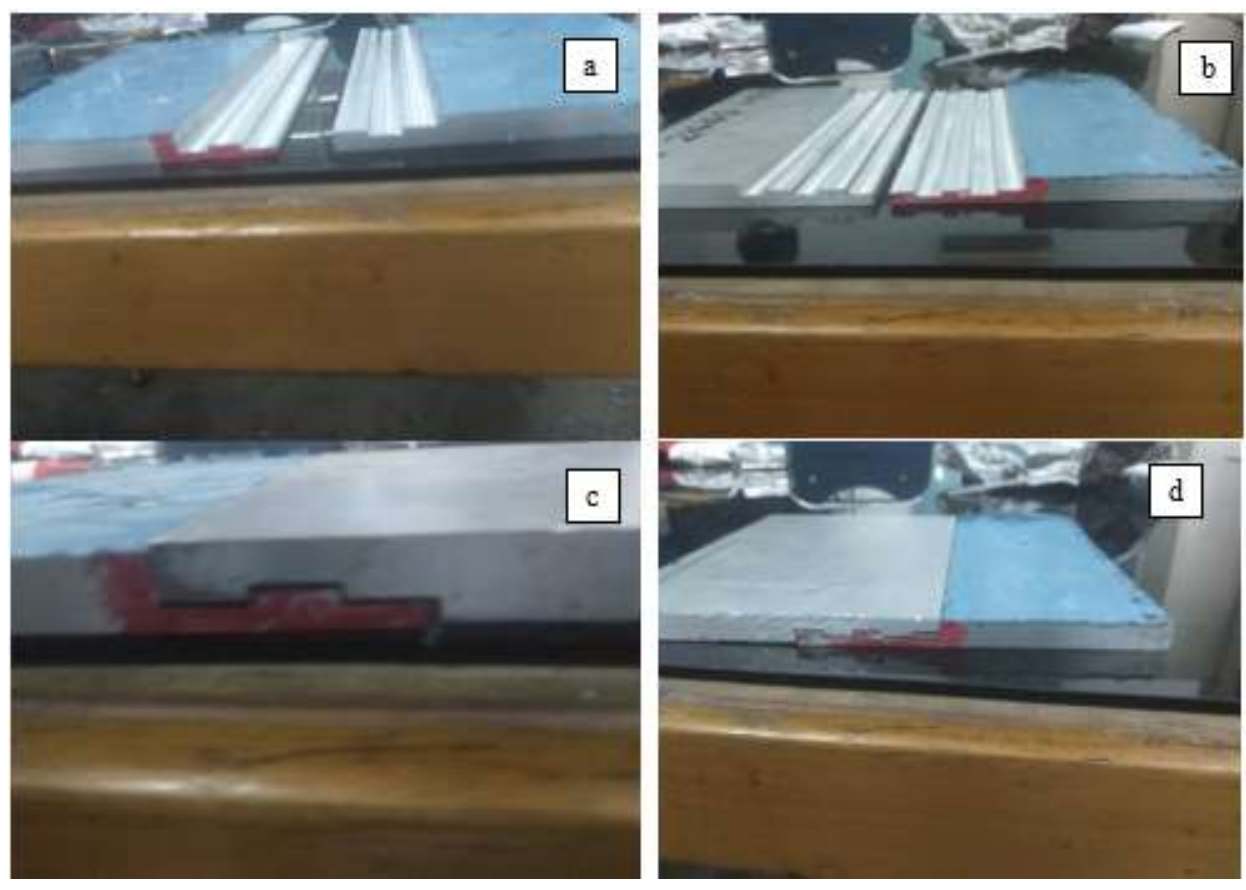

Fig. 6. Preparation of FSW samples. Single U and double joint design after CNC processing (a and b), designs that are paired before the FSW process ( $c$ and d) 


\section{Results and Discussions}

\section{A. Macrostructure}

Visually, the material produced by the friction stir welding process with the design single $\mathrm{U}$ and double $\mathrm{U}$, as shown by Figure 5 and Figure 6.
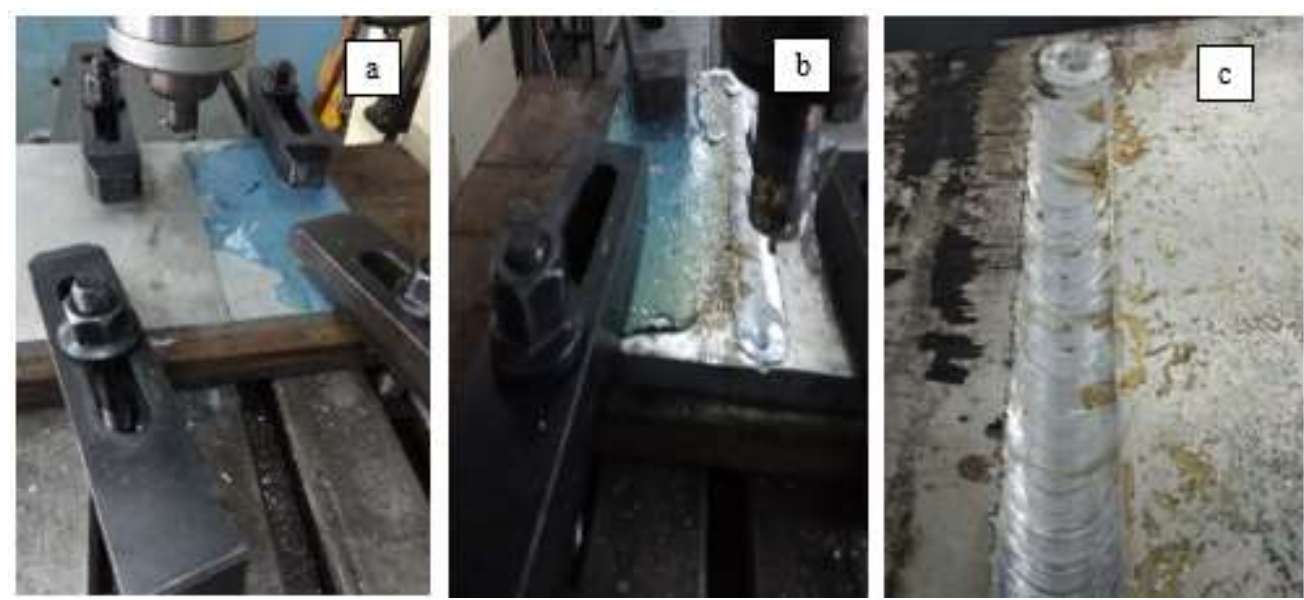

Fig. 7. a) FSW aluminum 6061 setting process, b) The FSW process is ongoing, c) Result of FSW the process in single $U$ design

The texture of the nuggets looks rough. This is due to the low heat energy of the probe below 0.8 TM (Temperature Melting) (Figure 7A); it also affects the hardness of the heat generated. The resulting texture is smooth due to high heat energy or reaches $0.8 \mathrm{TM}$ (Figure 7B). This will affect the hardness value and tensile test. The design of this welded joint does not affect the tensile strength that occurs; it only functions as a lock.
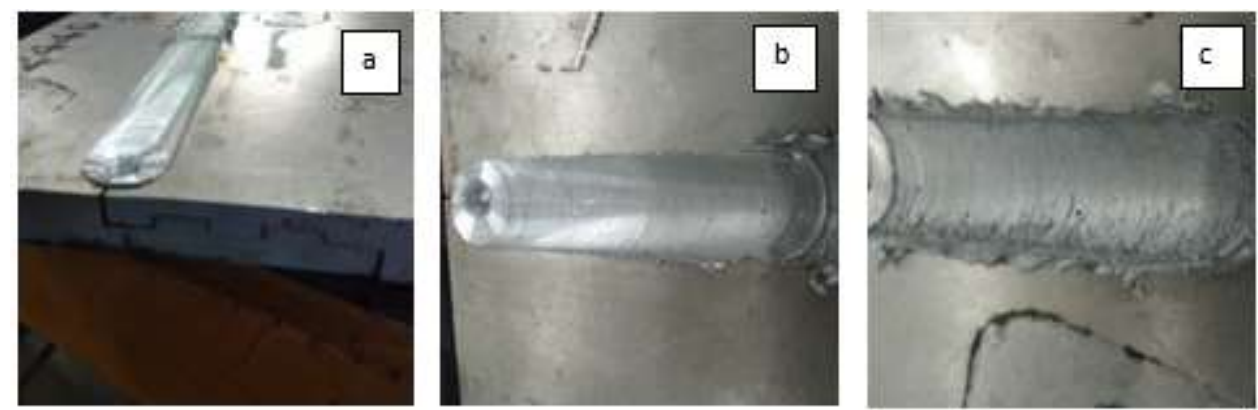

Fig. 8. a) FSW aluminum 6061 double U process, b) The process is good c) The process is not good

The double $\mathrm{U}$ joint design in Figure $8 \mathrm{a}$ and Figure $8 \mathrm{~b}$ is a pairing of the FSW process with good texture results. This will increase the locking strength of the joint. In Figure 8c, the texture of the image looks very rough. The chips appear on the advancing and retreating side due to the high probe pressure and high heat. Double U joint design fits well for FSW processing. The double $U$ tensile strength is better than the $U$ single due to the two protrusions as anchors. The FSW welding itself only functions as a lock so that it does not get separated from the welding pair.

\section{B. Temperature Measurement}

Temperature measurement is done manually, using a thermocouple which is attached to the workpiece. Recorded manually in several sections on a single $U$ or double $U$ connection and graphed. Results of temperature evolution is shown in Figure 9. 


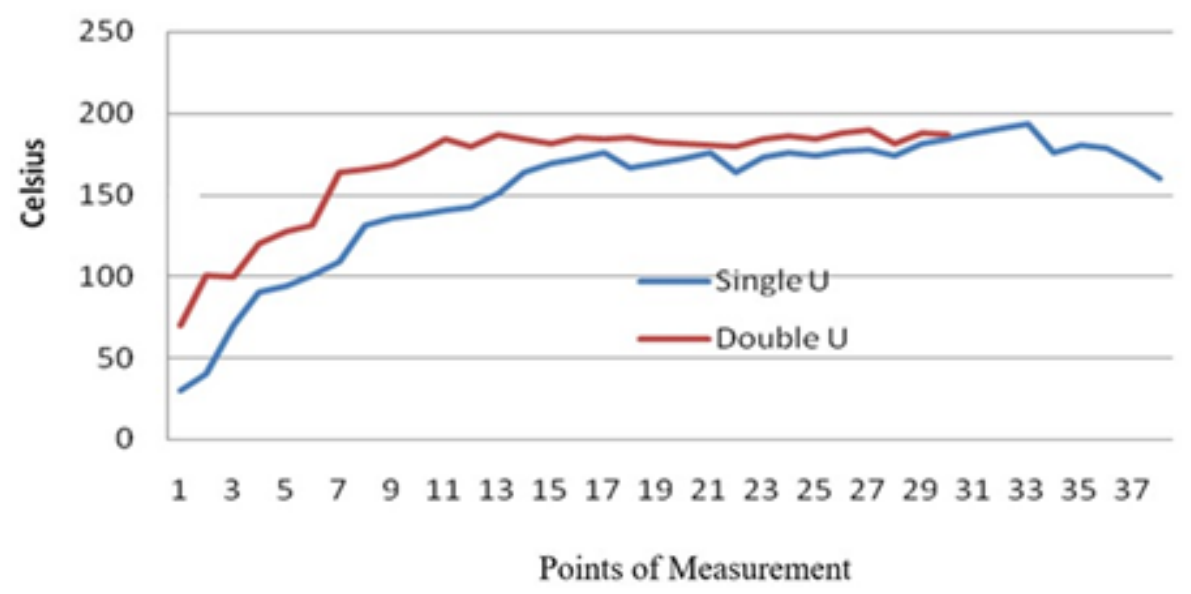

Fig. 9. The measurement temperature

Figure 9 show a low temperature below $200^{\circ}$ on both single $U$ and double U joints. At this temperature, a coarse microstructure will be produced, which will result in high Vickers hardness, but the resulting shear strength is high, also has not reached perfect plastic. As a result the mechanical properties that occur are not as expected, so as a result the microstructure contains little oxide and low hardness.

\section{Microstructure}

Figure 10 shows a lot of black spots are oxides trapped in the nugget area due to the position of the probe pin directly stirring the plastic material. The heat that occurs is high and the cold quickly due to the heat loose that results in an oxide layer on aluminum 6061. This oxide will reduce the mechanical properties of aluminum 6061.
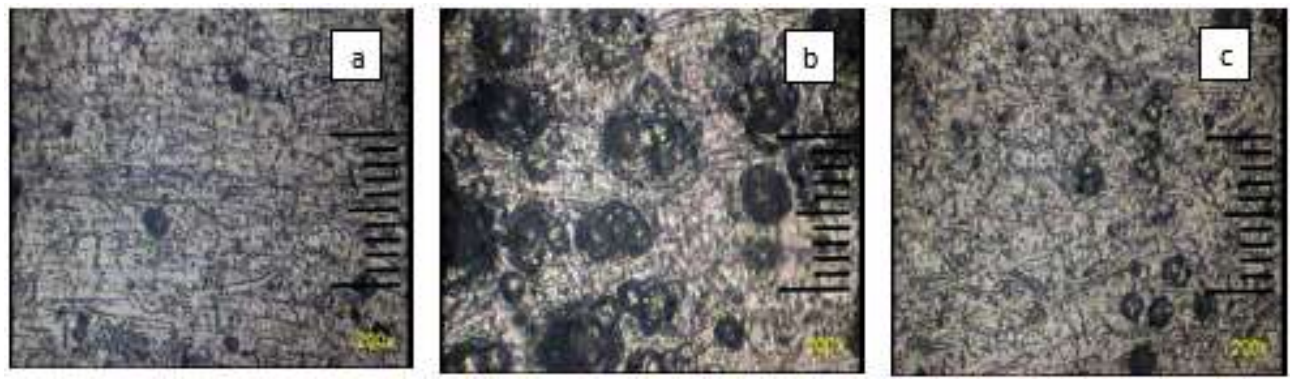

Fig. 10. (a) HAZ microstructure, (b) nuggets, and (c) TMAZ single U joining $200 \mathrm{x}$ magnification
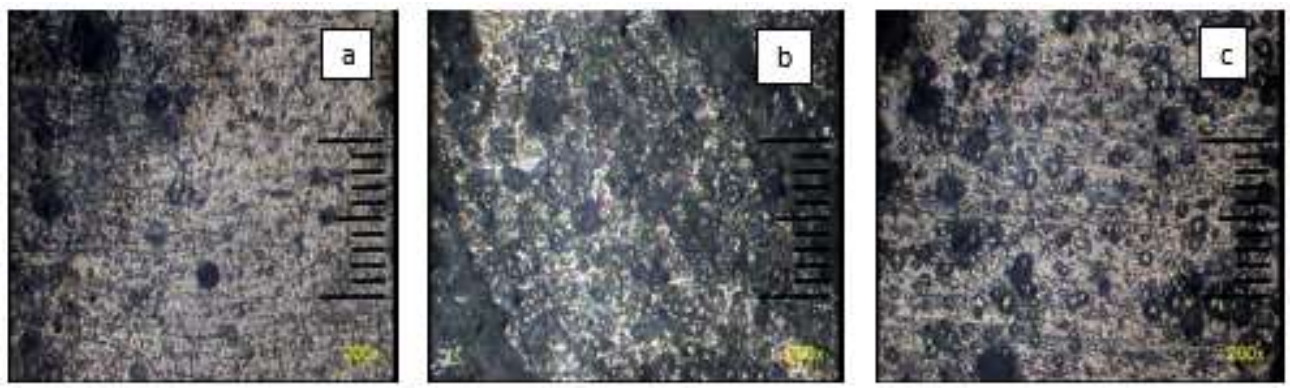

Fig. 11. (a) HAZ microstructure, (b) nuggets and (c) TMAZ double U joining $200 \mathrm{x}$ magnification 
The microstructure shown in the double $U$ joint is slightly different. The microstructure in the nuggets is mostly formed by oxides, this is due to the low temperature achieved or a very rapid decrease in temperature resulting in decreased mechanical properties. In TMAZ the microstructure that occurs is dominated by small oxides that are evenly distributed, this is due to the low process temperature.

\section{Micro Hardness Vickers Tests}

Hardness tested against aluminum 6061 with single $U$ and double $U$ designs using the Vickers method with a loading of 300 gf or $0.3 \mathrm{kgf}$. It can be seen that the double U design has a higher hardness than single U. This is because the heat energy at low FSW does not change the basic structure of 6061 aluminum, especially the magnesium $(\mathrm{Mg})$ content. The trapped oxide in the nugget will slightly increase the mechanical properties, especially hardness (Figure 11). Silica (Si) alloys have no effect on improving mechanical properties. Silica in aluminum alloy 6061 will increase the flowability of the casting material. The blue color is the hardness on the upper side is 52 - 69 VHn. Red color decreased Vickers microhardness, namely $45-50 \mathrm{VHn}$. This is because the high heat energy (0.8 TM) will cause a decrease in the hardness value, also the oxide trapped in the nugget will reduce its mechanical properties, especially hardness (Figure 12).
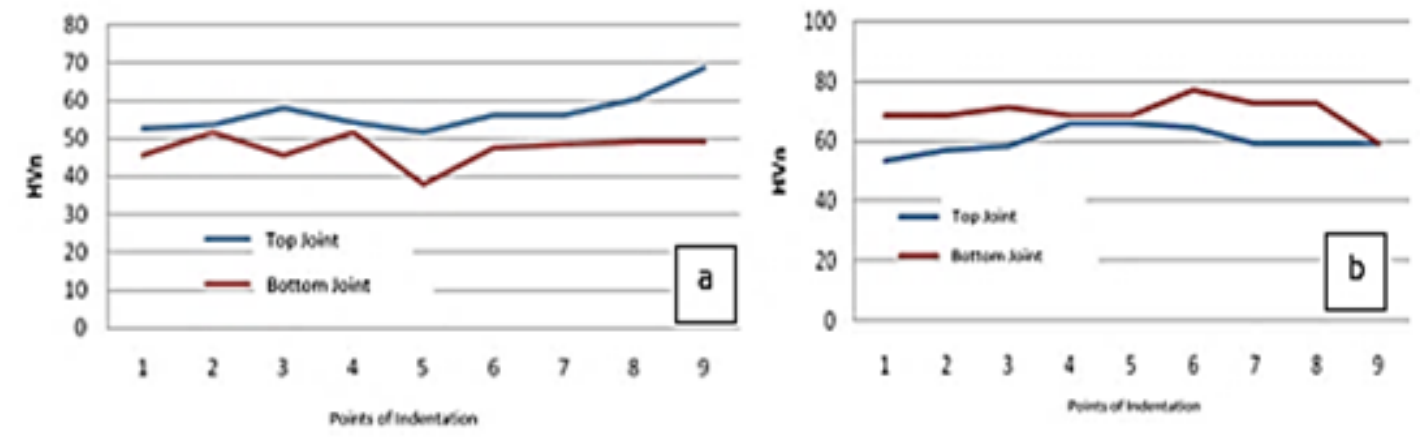

Fig. 12. Vickers hardness (a) Single U joint, (b) Double U joint at $300 \mathrm{gf}$ load

\section{E. Tensile Force Tests}

Figure 13 shows tensile test results. The highest tensile strength at the double $U$ joint is $13.5 \mathrm{kN}$, the lowest is $10 \mathrm{kN}$, while the average tensile strength is $12 \mathrm{kN}$.

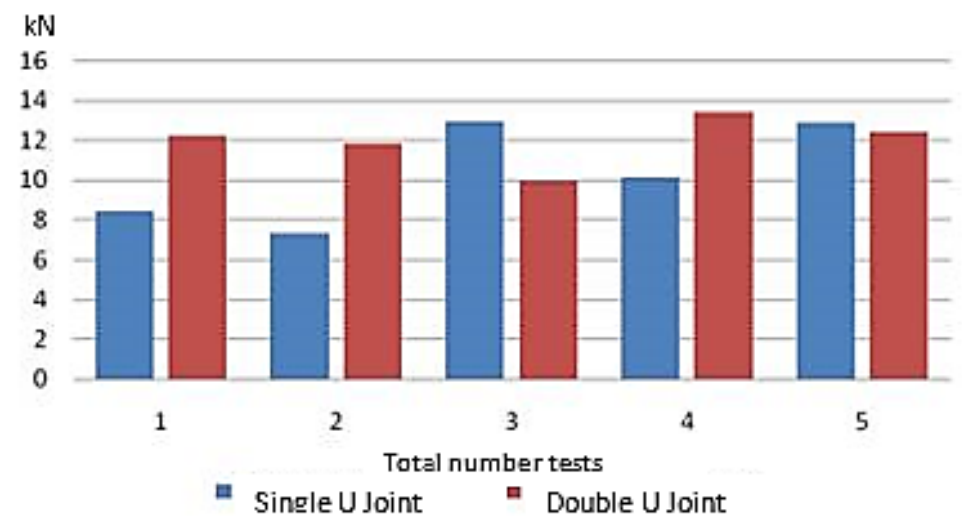

Fig. 13. Tensile force of single $U$ joint and double U joint after FSW 
FSW welded joint only functions as a lock, while the tensile strength is focused on the joint design. The double $U$ joint design has a major influence on the tensile strength of the test. Single U joint design, the highest tensile strength is $12.9 \mathrm{kN}$, the lowest is $7.35 \mathrm{kN}$, while the average tensile strength is $10.37 \mathrm{kN}$. This tensile test is high; this is due to the joint design as a strength enhancer. Nugget, TMAZ, and HAZ on the weld have functioned as fastening only.

\section{Conclusions}

FSW for 6061 aluminum using single $U$ and double $U$ joint was evaluated. The joint design studied has good tensile strength and will provide information about the newly designed joints in the FSW welding method. The nugget, TMAZ, and HAZ only function as locks, while their shear strength lies in the joint design.

\section{Acknowledgement}

The authors full thank to Head of LIPI Laboratory.

\section{References}

[1] Thomas, W.M., Friction Stir Butt Welding, International Patent Application No PCTrGB92 Patent Application No.9125978.8, 1991.

[2] Vaughn G., A., Microstructural Study of Friction Stir Welded Joints of Carbon Steels, Exxon Mobil Upstream Research Company, Houston, Texas, USA, 2004.

[3] Thomas W. M. and Nicholas E. D., Friction stir welding for the transportation industries, TWI, Abington Hall, Abington, Cambridge CB1 6AL, 1997.

[4] Lienert, T. J., Stellwag, W. L. JR., Grimmett, B. B., and Warke, R. W., "Friction Stir Welding Studies on Mild Steel”, Supplement to Welding Journal, pp. 1-9, January 2003

[5] Li B., Shen Y, A., "Feasibility research on friction stir welding of a new-typed lapbutt joint of dissimilar Al alloys", Materials \& Design, vol. 34, pp. 725-731, Pebruary 2012.

[6] Nandan, R., DebRoy, T., Bhadeshia, H.K.D.H., "Recent advances in friction-stir welding - Process, weldment structure and properties", Progress in Materials Science, vol. 53, pp. 980-1023, 2008.

[7] Nelley, Mc. T.R., Swaminathan, S., Su, J.Q., "Recrystallization mechanisms during friction stir welding/processing of aluminum alloys", Scripta Mater, vol 58(5), pp. 349-345, 2008

[8] Gao, Y., Nakata, K., Nagatsuka, K., Liu F.C., Liao J., "Interface microstructural control by probe length adjustment in friction, stir welding of titanium and steel lap join", Materials \& Design, vol. 65, pp. 17-23, 2014.

[9] Silva, A. C. F., Braga, D. F. O., de Figueiredo, M. A. V. and Moreira, P. M. G. P., "Friction stir welded T-joints optimization", Materials \& Design, vol. 55, pp.

$120-127,2014$. 
[10] Padgett, P.N., Paglia, C., and Buchheit, R.G., "Characterization of corrosion behaviour in friction stir weld Al-Li-Cu AF/C458 Alloy", Friction stir welding and processing II. USA: Warrendale, 2003.

[11] Mortensen, K. S., Jensen, C.G., Conrad, L.C. and Losee, F., Mechanical properties and microstructures of inertia-friction-welded 416 stainlessteel, Utah: Departement of Mechanical, Brigham Young University, 2011.

[12] Ozekcin, A., Jin, H.W., Koo, Y.J., Bangaru, N.V., Ayer, R., Vaughn, G.A, "Microstructural study of friction stir welded joints of carbon steels", The International Society of Offshore and Polar Engineers, 2004.

[13] Malarvizhi, S. and Balasubramanian, V., "Influences of tool shoulder diameter to plate thickness ratio $(\mathrm{D} / \mathrm{T})$ on stir zone formation and tensile properties of friction stir welded dissimilar joints of AA6061 aluminum-AZ31B magnesium alloys", Materials \& Design, vol. 40, pp. 453-460, 2003

[14] Setiawan, W., Darmadi D.B., Suprapto W., Soenoko, R., "The position of the joints with angle of $90^{\circ}$ at friction stir welding (FSW)", MM Science Journal, vol. 2017, pp. 2128-2135, 2018. 